\title{
Analysis of Flowrate in Loop Gas Pipeline Networks Using Pipe 2016 and Hardy Cross Method

\author{
OMOBOLANLE Oluwasegun Cornelious"
}

Student, Department of Petroleum Engineering University of Ibadan, Ibadan Oyo state, Nigeria

\author{
DOI: $10.36348 /$ sjet.2020.v05i02.003 \\ | Received: 08.02.2020 | Accepted: 15.02.2020 | Published: 19.02.2020 \\ *Corresponding author: OMOBOLANLE Oluwasegun Cornelious
}

\section{Abstract}

Efficient and increased development of gaseous fuel as a complementary energy source requires a proper understanding of gas flow through pipeline networks and the required solution methods. This paper presents a comparative analysis of flowrate in loop gas pipeline systems using the Hardy Cross iterative method and Pipe 2016 (KYPIPE) computer program. A simple network model with four nodes, five pipe legs and two loops was manually analyzed based on the Hardy Cross procedure using Excel spreadsheet while comparing the effect of friction factors obtained from Moody's chart, Colebrook's implicit equation and Jain's explicit equation on the result obtained from the Hardy Cross method. The accuracy of the result was validated by running a single period flow analysis on Pipe 2016 with the same network. Upon completion, a one-way analysis of variance (ANOVA) test was used to compare the four results while a T-test was used to double-check the three results obtained from the various friction factors based on Hardy Cross individually against the software's result. Although, the mean plot showed that values obtained from Moody's Chart and Colebrook's equation compared more accurately with the software, the AVONA and T-test set at 5\% significant level shows that no statistically significant difference exist between the results; making all friction factors suitable for use in gas pipeline flow analysis.

Keywords: Gas pipeline networks, Hardy Cross method, KYPIPE, Pipe 2016, Flow analysis, Loop Pipe, Friction factor.

Copyright @ 2020: This is an open-access article distributed under the terms of the Creative Commons Attribution license which permits unrestricted use, distribution, and reproduction in any medium for non-commercial use (NonCommercial, or CC-BY-NC) provided the original author and source are credited.

\section{INTRODUCTION}

The world's ever increasing energy demand has made natural gas production and transmission a problem for all stakeholders. Being the cleanest form of energy, natural gas provides daily supply of energy required for both industrial and domestic use. Natural gas can be transported through Ships, Tanked cars (Railway), tanked trucks (Trucks) and Pipelines. The method adopted to move the gas depends on the nature of the gas, the volume of the gas, the destination/terrain and the frequency of demand [1]. However, pipeline has been described as the best means of gas transport. They are safer, cheaper and environmentally friendlier. According to STRATA, in America, transport by pipeline accounts for only $1.7 \%$ of annual fatalities to operators as opposed to $2.4 \%$ and $10 \%$ by rail and trucks respectively, also it cost about $\$ 5$ per barrel to transport oil and gas by pipeline compared to between \$10-\$20 per barrel for rail and trucks. The 2013 United State Energy Information Administration report also has it that majority of oil spills occur at the facility rather than in actual pipeline except when vandalized, these facilities are designed to contain spills quickly and as such pipeline spills boast a high product recovery [2]. In view of the foregoing, a thorough understating of gas pipeline network topology and the required solution methods to the resulting non-linear equations is essential.

There are various methods used for analyzing pipeline network systems depending on the complexity of the network, the associated node connecting elements, the degree of accuracy and the level of convergence required. The Hardy Cross method is reputed as the oldest systematic method for solving pipeline network related problems before the availability of digital computers in the late 1960s [3], the method is an adaptation of the Moment distribution method, which was develop as a way to determine the moments in indeterminate structures but was later adapted to loop pipeline analysis. This method solves the loop equations by adjusting the flowrate to balance the energy equations [4], the results obtained per iteration are the correction of flow $(\Delta \mathrm{Q})$ rather than the flow (Q) obtained from using the loop-node method. Generally, there are four basic methods used to analyze 
pipe networks, they are; the Hardy Cross method, the Node method, the Loop method and the Loop-node method. The node method is based on Kirchhoff first law (which states that the algebraic sum of the flows at any node is zero) while the loop method is based on Kirchhoff's second law (which state that the pressure drop around any closed loop is zero). The Loop-node method is a synergy of both the node and the loop method. The Hardy Cross method is widely preferred of the four methods because it is less sensitive to initial value prediction [5].

Today, various computer programs have been developed to analysis loop pipeline networks but most of these software are only suited for analysis of water flow in pipeline. KYPIPE (Pipe 2016) can be used to calculate steady state flows and pressures for any liquid and gas flow in pipeline systems. The program is written to accommodate any piping configuration, hydraulic components, fittings, flow meters and storage tanks [6]. It also allows flexibility of unit as computations can be carried out using both English and SI units. KYPIPE solution approach solves the full set of mass continuity and energy equations by utilizing efficient linearization schemes to handle the non-linear terms and a very powerful spare matrix routine developed by A.R. Curtis and J.K. Reid of the Theoretical Physics Division, UKAEA Research Group, Harwell, England. This approach accommodates elements such as closed lines, check valves, and regulating valves in a direct and very efficient manner, giving the best convergence characteristic when compared with other software [7].

Since the accuracy of a solution method in determining the resulting flowrate in pipeline is a function of the friction factor used, there is a need for comparison amongst the available equations to determine the optimum friction factor to use for such calculations. The aim of this paper is to make a comparative analysis of flowrate using the Hardy Cross method and Pipe 2016. Also, this paper seeks to compare the effect of using three differently obtained friction factors (Moody's chart, Colebrook implicit equation and Jain's explicit equation) on the results obtain from the Hardy Cross method. For effective illustration of solution technique, the network is limited to a rectangular arrangement with four nodes, five pipe legs and two loops.

\section{MATERIAL AND METHODS MATERIALS}

The materials used in this project are

- $\quad$ KYPIPE Software (PIPE 2016) [8]

- Microsoft Excel spreadsheet for manual computation of Hardy Cross.

- Fortran 95 compiler [9]

\section{METHODS}

KYPIPE software (PIPE 2016) and Hardy Cross method were used for the analysis. Short FORTRAN 95 programs were also written to execute and determine the friction factors based on the initial assumed flowrates for the Jain explicit equation and the Colebrook implicit equation used in the Hardy Cross. This was done particularly for the Colebrook implicit equation to allow the program run a series of iteration for the friction factor until the optimum value that satisfies the equation is determined. The moody friction factor was obtained from Moody's chart. A copy of the written FORTRAN 95 programs is attached to the appendix.

\section{Method 1: solution approach to selected network using hardy cross method}

The simple network chosen for analysis is given below;

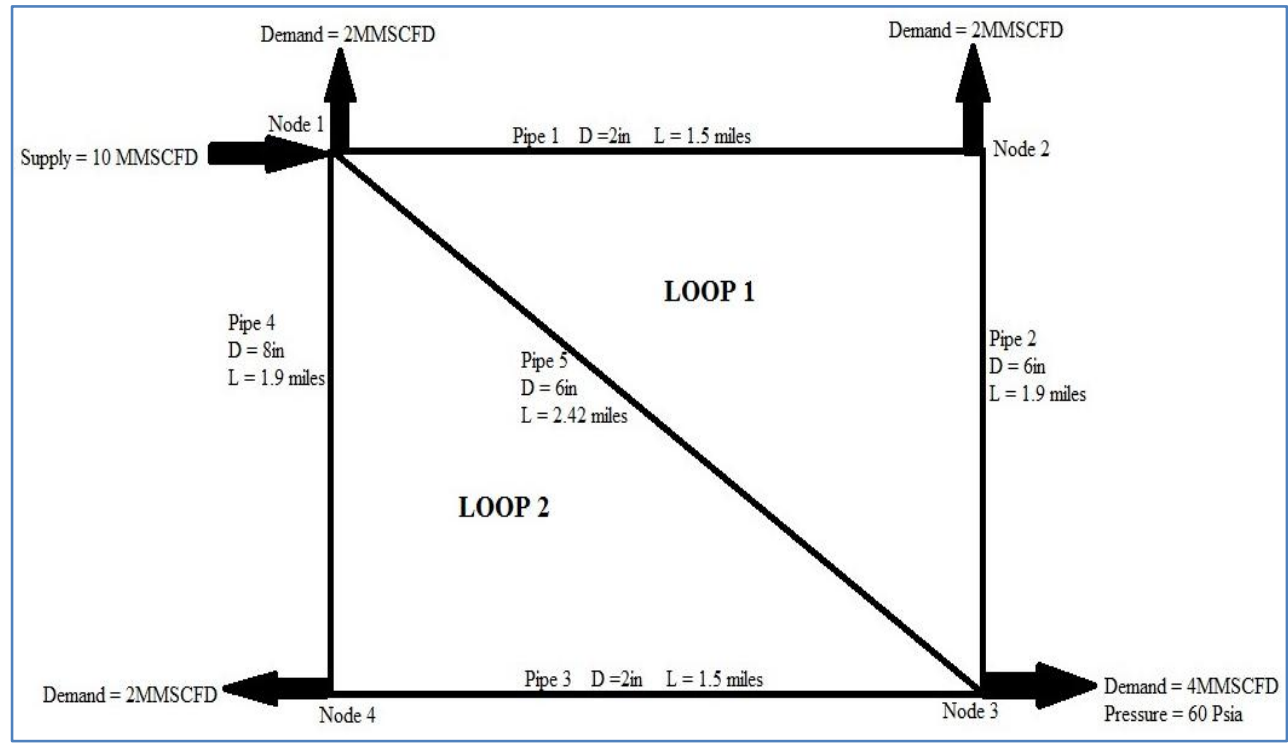

Fig-1: Selected Network 
Given, Gas specific gravity $=0.67$, Pipe roughness $=$ $0.0006 \mathrm{ft}$

Base Pressure $=14.7$ Psia Base Temperature $=60^{\circ} \mathrm{F}$

Elevation changes are neglected

Where:

$\mathrm{D}=$ Diameter $\quad \mathrm{L}=$ Length

Node: Junction Point, where fluid enters or leaves the networks

Loop: Closed path of interconnected pipes and nodes
Supply: Inflow into the network

Demand: Outflow from the network

\section{Step 1: Making an initial guess of flow}

An initial guess of possible flowrate and flow direction in pipe was made bearing in mind that the total inflow at each node must be equal to the total outflow at each junction.

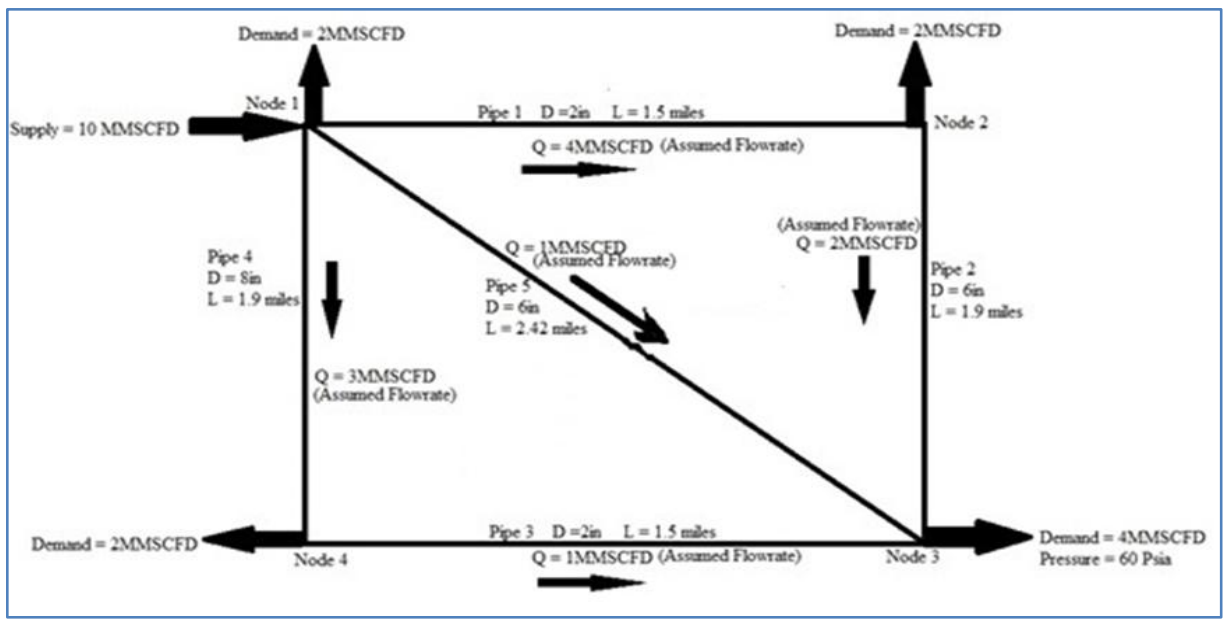

Fig-2: Assumed flow and direction

\section{Step 2: Data Preparation}

\section{Unit Conversion}

Although quantities in the Oil and Gas industry are measured in Field unit (English Unit), the Hardy Cross method uses S.I. unit and as such all parameters including length, diameter and flowrate were converted to S.I. unit.

$1 \mathrm{MMSCFD}=0.32755 \mathrm{M}^{3} / \mathrm{Sec}$

1 Miles $=1609.344$ Meters

1 Inches $=0.0254$ Meters

Table-1: Conversion of Parameters

\begin{tabular}{|c|c|c|c|c|c|c|}
\hline Pipe & $\begin{array}{c}\text { Assumed Q } \\
\text { (MMSCFD) }\end{array}$ & Q $\left(\mathbf{M}^{\mathbf{3}} / \mathbf{S e c}\right)$ & L (Miles) & L (M) & D (in) & D (M) \\
\hline Pipe 1 & 4.0000 & 1.3102 & 1.5000 & 2414 & 2.0000 & 0.0508 \\
\hline Pipe 2 & 2.0000 & 0.6551 & 1.9000 & 3058 & 6.0000 & 0.0205 \\
\hline Pipe 3 & -1.0000 & -0.3276 & 1.5000 & 2414 & 2.0000 & 0.0508 \\
\hline Pipe 4 & -3.0000 & -0.9827 & 1.9000 & 3058 & 8.0000 & 0.2032 \\
\hline Pipe 5 & -1.0000 & -0.3276 & 2.4200 & 3895 & 6.0000 & 0.1524 \\
\hline
\end{tabular}

\section{Determination of Friction Factor}

The friction factor used was obtained from Moody's chart, Jain equation and Colebrook equation. Fortran 95 Programs were written to execute and determine the friction factor for Jain and Colebrook using their equations. The program is essential to allow Colebrook run a series of iteration for the friction factor until the optimum value that satisfies the equation is determined.

Jain explicit equation is give as

$\frac{1}{\sqrt{F}}=1.14-2 \log \left(\frac{e}{D}+\frac{21.25}{N_{R e}^{0.9}}\right)$

Equation 1

Colebrook Implicit equation is given as

$\frac{1}{\sqrt{F}}=1.74-2 \log \left(\frac{2 e}{D}+\frac{18.7}{N_{R e} \sqrt{F}}\right)$

Equation 2

Where,

$\mathrm{N}_{\mathrm{Re}}=$ Reynold's Number $\quad \mathrm{F}=$ Friction factor $\mathrm{e}=$ Pipe roughness

$\mathrm{D}=$ Diameter

\section{Determination of Flow resistance}

The flow resistance is used to determine the effect of the various pipe properties on fluid flow (pressure losses). This depends on the hydraulic equation used; for this project, the Darcy-Weisbach equation was used. The head-loss and flow resistance are defined by equations 3 and 4 respectively.

$H_{f}=r * Q *|Q| \ldots \ldots \ldots \ldots \ldots$. Equation 3
$r=\frac{32 F l}{g \pi^{2} D^{5}} \ldots \ldots \ldots \ldots \ldots \ldots \ldots . . . \ldots q u a t i o n$

Where, $\mathrm{H}_{\mathrm{f}}=$ Head-loss $\quad \mathrm{Q}=$ Flowrate

$\mathrm{L}=$ Length $\quad \mathrm{g}=$ Acceleration due to gravity

$\pi=3.142 \quad \mathrm{~F}=$ Friction factor

$\mathrm{D}=$ Diameter of pipe $\quad \mathrm{r}=$ Flow resistance 
Step 3: Determination of closed loop and head-loss

The two closed loops in the system were identified and clockwise direction of flow was assumed positive for head loss analysis (flow in the anticlockwise direction are assigned negative flowrate). Equation 3 was used to calculate the head-loss. It should be noted that the total sum of head-losses in a loop should be equal to zero. The total head-loss was calculated by summing up the various calculated headlosses for each pipe within a loop.

Total Head loss $=\sum h f=\sum_{i}^{n}(r * Q *|Q|)$ .........Equation 5

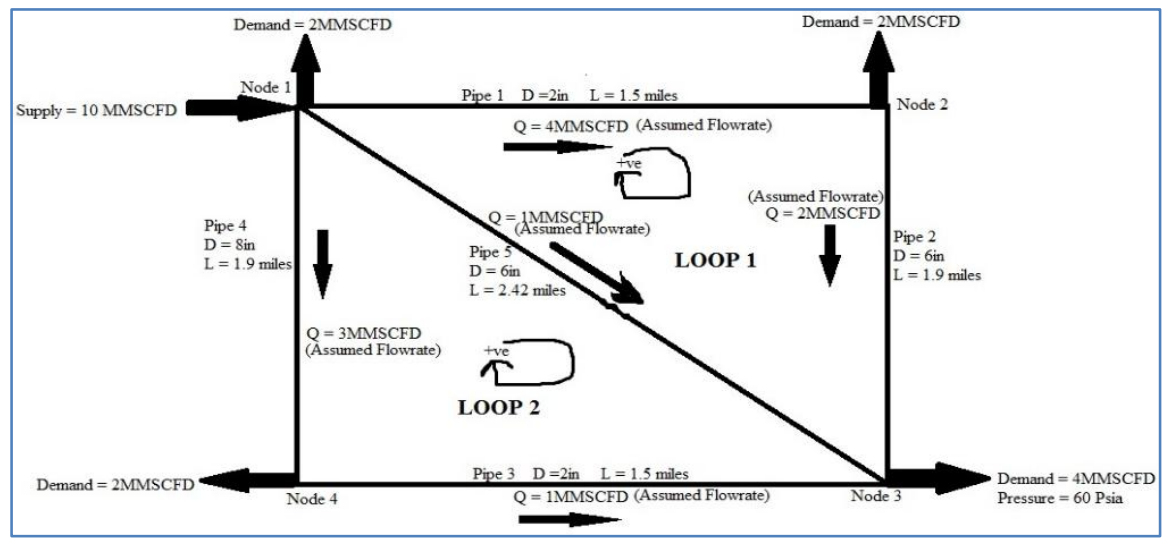

Fig-3: Identification of Closed loops

\section{Step 4: Determination of the correction factor}

Since an initial guess of flow was made for each pipe, balancing of head by the addition of a correction factor was done. This was done to achieve continuity of potential over the closed loop. The change in flow that will balance the head in the closed loop is given by:

$\Delta Q=\frac{-1 * \sum(r * Q *|Q|)}{\sum(2 * r *|Q|)}=\frac{-1 * \sum_{i=1}^{n} H f}{\sum_{i=1}^{n}(2 * r *|Q|)} \ldots \ldots \ldots$. Equation 6

The calculated change in flow is added up to the assumed flow $\mathrm{Q}_{0}$ for each pipe.

$\mathrm{Q}_{1}=\mathrm{Q}_{0}+\Delta \mathrm{Q}$. Equation 7

\section{Step 5: Correction for Joint Pipe}

For pipes that are shared by two or more loops, the flow in the pipes must be balanced to satisfy the conditions in the two loops; this is generally done by using the calculated value $\left(Q_{1}\right)$ for the pipe in the first loop as the $\mathrm{Q}_{0}$ for the same pipe in the second loop. Depending on the flow direction, $(-1)$ is used to multiply the $\mathrm{Q}_{0}$ now computed as $\mathrm{Q}_{1}$ to correct for direction change. The correction for flow and direction are repeated at every point the joint pipe appears for the two loops.

For instance, pipe 5 is shared between Loop 1 and 2, the assumed flow for pipe 5 and the direction assigned is used as its $\mathrm{Q}_{0}$ and direction in Loop 1; the head loss is calculated for this value and subsequently corrected based on the calculated $\Delta \mathrm{Q}$ for loop 1 . The corrected value $\mathrm{Q}_{1}$ for Pipe 5 in Loop 1 is then used as $\mathrm{Q}_{0}$ for Pipe 5 in Loop 2, since the direction of pipe 5 in loop 1 and 2 are opposite, (-1) is used to multiply the value thus $\mathrm{Q}_{0}$ for pipe 5 in loop 2 become $-1 * \mathrm{Q}_{1}$ (value obtained from pipe 5 in loop 1 ).

For the second iteration, the $\mathrm{Q}_{1}$ for pipe 5 in loop 2 of the first iteration becomes the $\mathrm{Q}_{0}$ for pipe 5 in loop 1 of the second iteration, change in direction is also corrected, therefore, $\mathrm{Q}_{0}$ in loop 1 becomes $-1 * \mathrm{Q}_{1}$ (value obtained from pipe 5 in loop 2 of iteration 1 ). This is done for every shared pipe across loops but for this network, only pipe 5 is shared. The iteration is repeated until $\Delta \mathrm{Q}=0$.

$$
\text { If } \Delta \mathrm{Q}=0 \text {, then } \mathrm{Q}_{1}=\mathrm{Q}_{0} \text {. }
$$

\section{Step 6: Repetition of process}

Step 1-5 is repeated using values obtain for the other friction factors. The table below shows a model of the first iteration using values obtained from Moody's chart. The result obtained from the whole analysis for the three friction factor is presented in the result and discussion section of this paper. 
Model for Hardy Cross Calculation

Table-2: Table Illustrating Hardy Cross using values obtained from Moody's chart

\begin{tabular}{|c|c|c|c|c|c|c|c|c|c|c|}
\hline & & Pipe & $\begin{array}{c}\mathrm{Q}_{\mathrm{O}} \\
\text { (mmscfd) }\end{array}$ & $\begin{array}{c}\mathrm{Q}_{\mathrm{o}} \\
\left(\mathrm{m}^{3} / \mathrm{sec}\right)\end{array}$ & $\mathrm{F}$ & $\mathrm{r}$ & $\mathrm{H}_{\mathrm{f}}=\mathrm{rQ}|\mathrm{Q}|$ & $2 \mathrm{r}|\mathrm{Q}|$ & $\begin{array}{c}\Delta \mathrm{Q}= \\
\frac{-1 * \sum r * Q *|Q|}{2 * r *|Q|}\end{array}$ & $\begin{array}{c}\mathrm{Q}_{1} \\
=\mathrm{Q}_{0}+\Delta \mathrm{Q}\end{array}$ \\
\hline & & $\begin{array}{l}\text { Pip } \\
\text { e } 1\end{array}$ & 4.0 & 1.3120 & $\begin{array}{c}0.027 \\
6\end{array}$ & $\begin{array}{c}6513873 \\
6\end{array}$ & $\begin{array}{c}11181872 \\
0\end{array}$ & $\begin{array}{c}17068954 \\
4\end{array}$ & -0.6534612 & $\begin{array}{c}0.65673877 \\
3 \\
\end{array}$ \\
\hline & $\begin{array}{l}\text { Loo } \\
\text { p } 1\end{array}$ & $\begin{array}{l}\text { Pip } \\
\text { e } 2\end{array}$ & 2.0 & 0.6551 & $\begin{array}{c}0.020 \\
5\end{array}$ & $\begin{array}{c}252219 . \\
1\end{array}$ & $\begin{array}{c}108241.36 \\
2 \\
\end{array}$ & $\begin{array}{c}330457.52 \\
3 \\
\end{array}$ & -0.6534612 & $\begin{array}{c}0.00163877 \\
3 \\
\end{array}$ \\
\hline & & $\begin{array}{l}\text { Pip } \\
\text { e } 5\end{array}$ & -1.0 & -0.3276 & $\begin{array}{c}0.020 \\
5\end{array}$ & $\begin{array}{c}321253 \\
6\end{array}$ & $\begin{array}{c}- \\
34477.503\end{array}$ & $\begin{array}{c}210485.37 \\
1\end{array}$ & -0.6534612 & $\begin{array}{c}- \\
0.98106122 \\
7\end{array}$ \\
\hline \multirow[t]{5}{*}{$\begin{array}{c}\text { Iteratio } \\
\text { n } 1\end{array}$} & & & & & & $\sum^{n} x$ & $\begin{array}{c}11189248 \\
4\end{array}$ & $\begin{array}{c}17123048 \\
7\end{array}$ & & \\
\hline & $\begin{array}{l}\text { Loo } \\
\text { p } 2\end{array}$ & $\begin{array}{l}\text { Pip } \\
\text { e } 3\end{array}$ & -1.0 & -0.3276 & $\begin{array}{c}0.027 \\
6\end{array}$ & $\begin{array}{c}6513873 \\
6\end{array}$ & $\begin{array}{c}- \\
6990803.8\end{array}$ & $\begin{array}{c}42678899 \\
9\end{array}$ & 0.15512749 & $\begin{array}{c}- \\
0.17247250 \\
8\end{array}$ \\
\hline & & $\begin{array}{l}\text { Pip } \\
\text { e } 4\end{array}$ & -3.0 & -0.9827 & $\begin{array}{c}0.019 \\
1\end{array}$ & $\begin{array}{c}55765.2 \\
8\end{array}$ & $\begin{array}{c}- \\
53852.489 \\
4 \\
\end{array}$ & $\begin{array}{c}109601.07 \\
7\end{array}$ & 0.1551274 & $\begin{array}{c}- \\
0.82757250 \\
8\end{array}$ \\
\hline & & $\begin{array}{l}\text { Pip } \\
\text { e } 5\end{array}$ & $\begin{array}{c}2.995149 \\
5 \\
\end{array}$ & $\begin{array}{c}0.98106122 \\
7 \\
\end{array}$ & $\begin{array}{c}0.020 \\
5 \\
\end{array}$ & $\begin{array}{c}321253 . \\
6 \\
\end{array}$ & $\begin{array}{c}309200.54 \\
7 \\
\end{array}$ & 630338.94 & 0.1551274 & $\begin{array}{c}1.13618871 \\
9 \\
\end{array}$ \\
\hline & & & & & & $\sum_{1}^{n} x$ & $\begin{array}{c}- \\
6735455.7 \\
4 \\
\end{array}$ & $\begin{array}{c}43418839 . \\
9\end{array}$ & & \\
\hline
\end{tabular}

\section{METHOD 2: SOLUTION APPROACH TO SELECTED NETWORK USING KYPIPE (PIPE 2016)}

KYPIPE was used to analyze the flow in the selected network below;

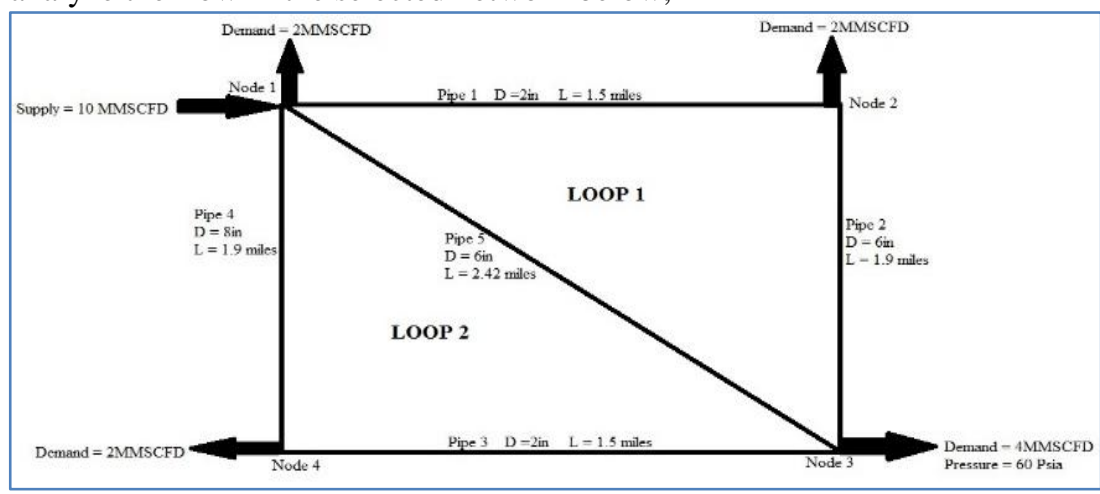

Fig-4: Selected Network

Step 1 - Initial Preparation

Initial steps include file selection, background preparation, and system data selections.

File Selection - Pipe 2016 was launched and a new data file was created.

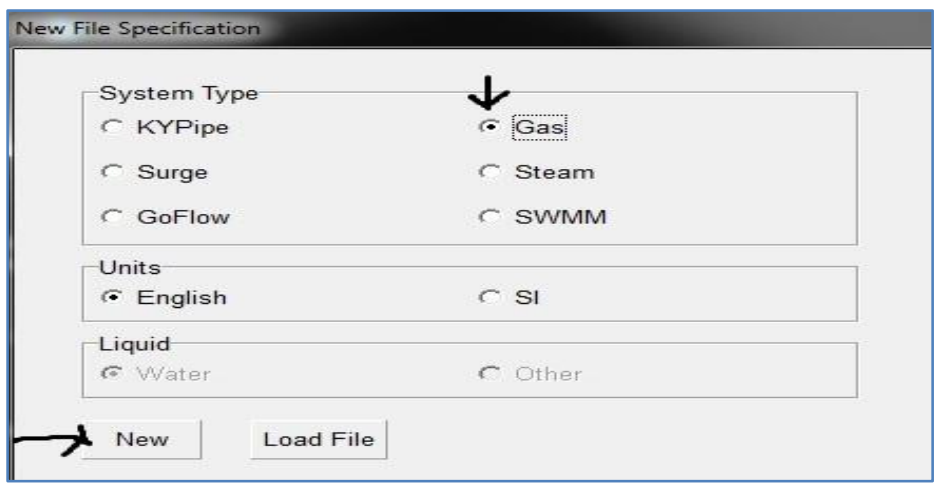

Fig-5: New file specification on KYPIPE (Pipe 2016) 
OMOBOLANLE Oluwasegun Cornelious., Saudi J Eng Technol, Feb. 2020; 5(2): 49-62

System Data Selection - It was used to specify system data such as Unit for flow rate, the default head loss equation (Hazen-Williams or Darcy-Welsbach's equation), the fluid property and other network and flow associated defaults. For this project, Darcy-
Welsbach head loss equation was used, also English unit was unit and the flowrate was in MSCFD as opposed to the MMSCFD in the network, so the values were multiplied by 1000 to accommodate for unit difference.

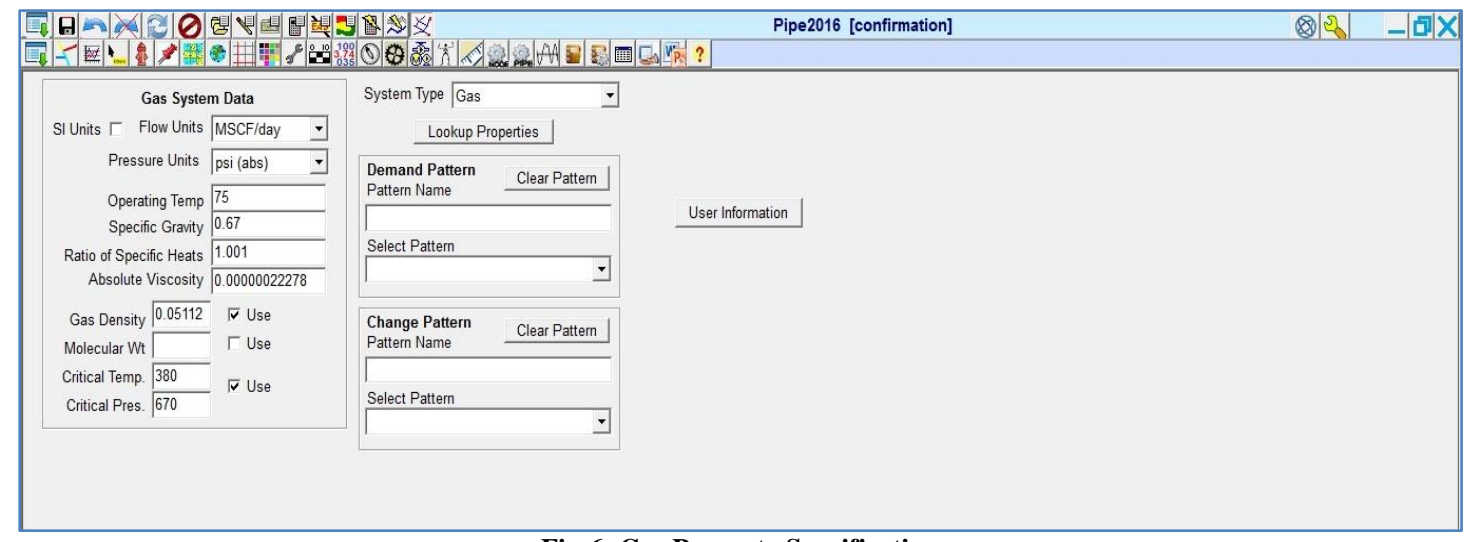

Fig-6: Gas Property Specification

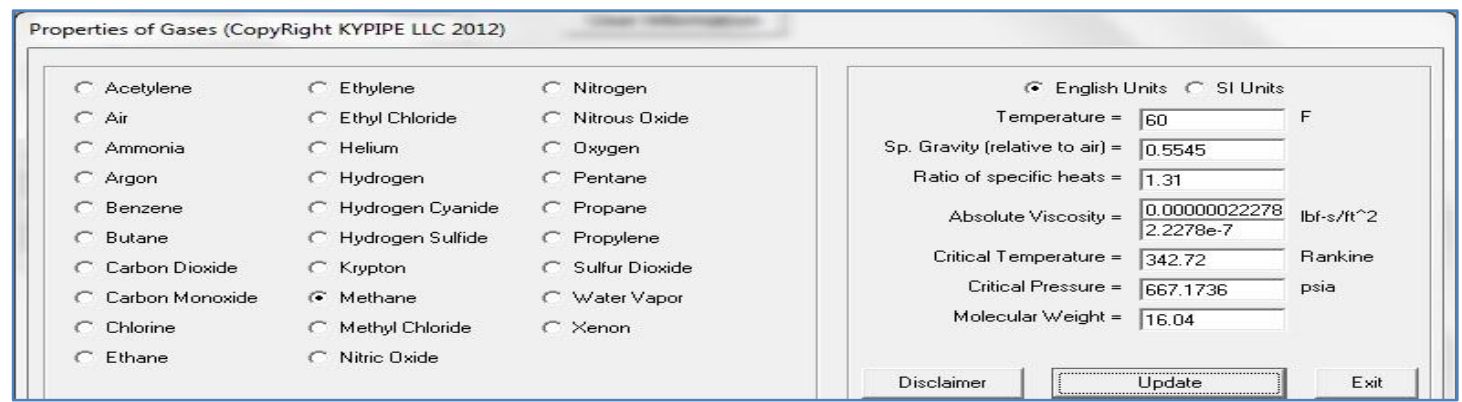

Fig-7: Selecting of Gas for property determination

Background Preparation: This is generally used to import a drawing, map image, utilize grid lines or choose not to use a background. For area with welldefined aerial map, such map can be downloaded for upload for proper layout definition. Skeletonized image of the network pipe distribution was drawn on the selected grid with specification of distance between points.

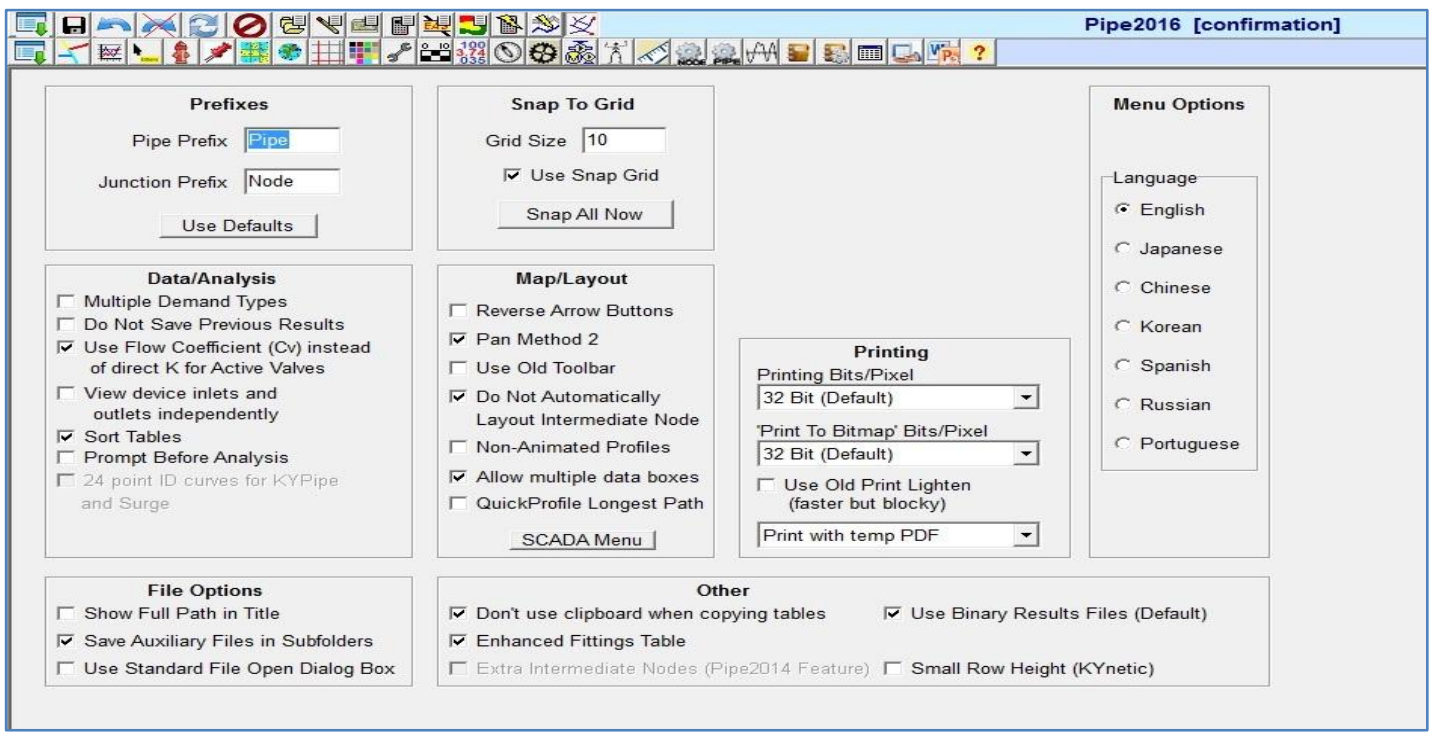

Fig-8: Grid Selection 


\section{Step 2 - System Layout}

The system was laid out accordingly on the grid and relevant pipe specifications (including pipe length, diameter, roughness and material), node demand and supply were made.
Pipe Layout: Single Right click was used to add Junction node, while pipes were automatically laid between junctions.

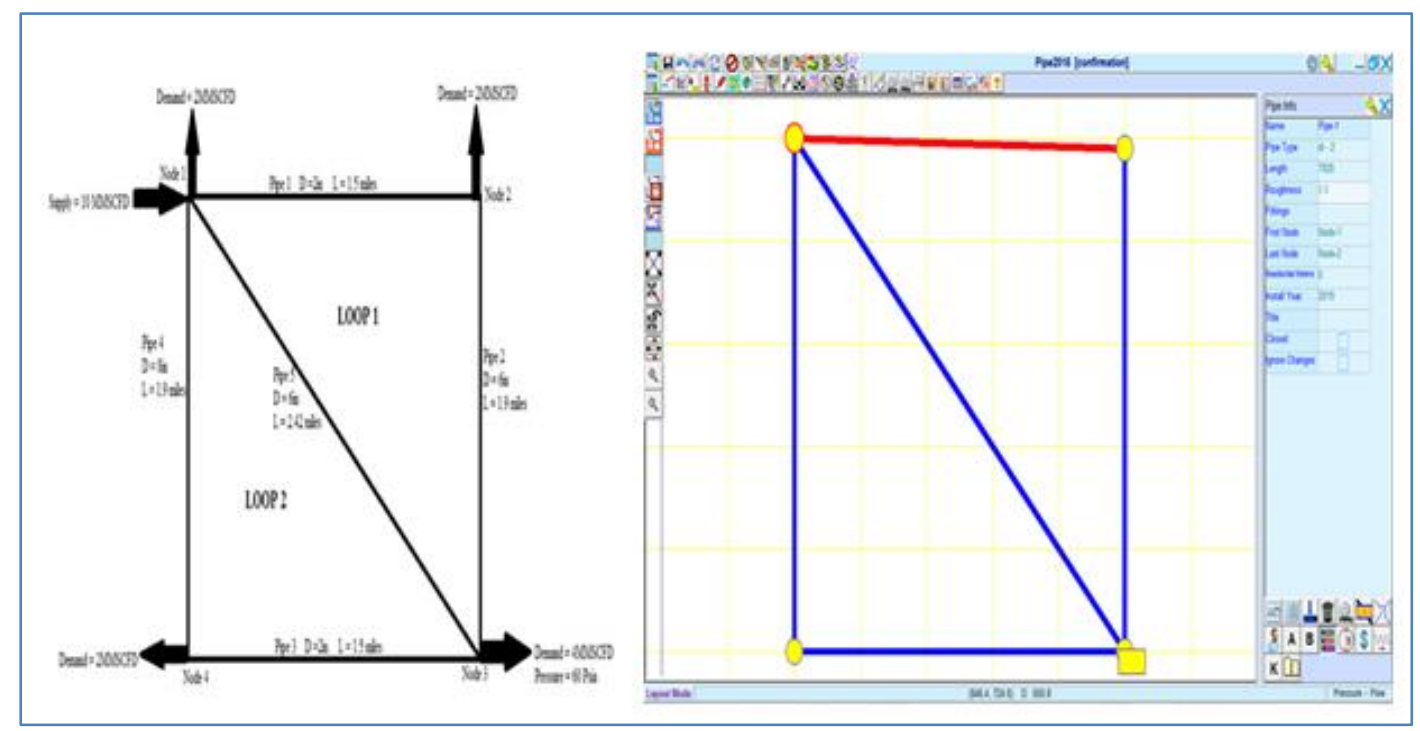

Fig-9: Pipe layout of sturcture

Pipe data specification: This was used to edit pipe properties for each pipe, each pipe was left click upon to edit its properties.

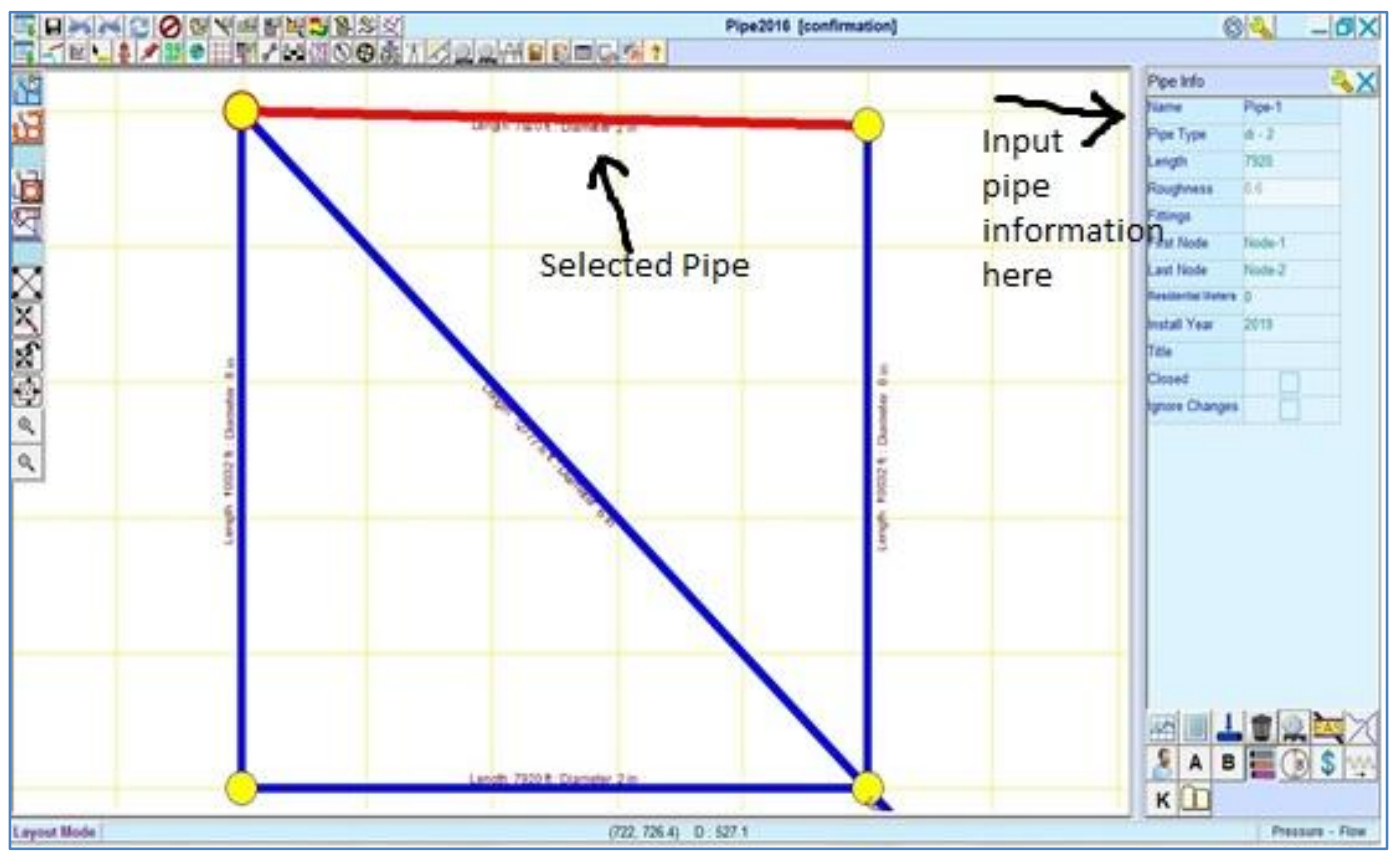

Fig-10: Pipe data specification

Node data specification: Node demand and supply were computed for each node, pressure was also specified for fixed grade node(nodes where demand pressure required is specified). 


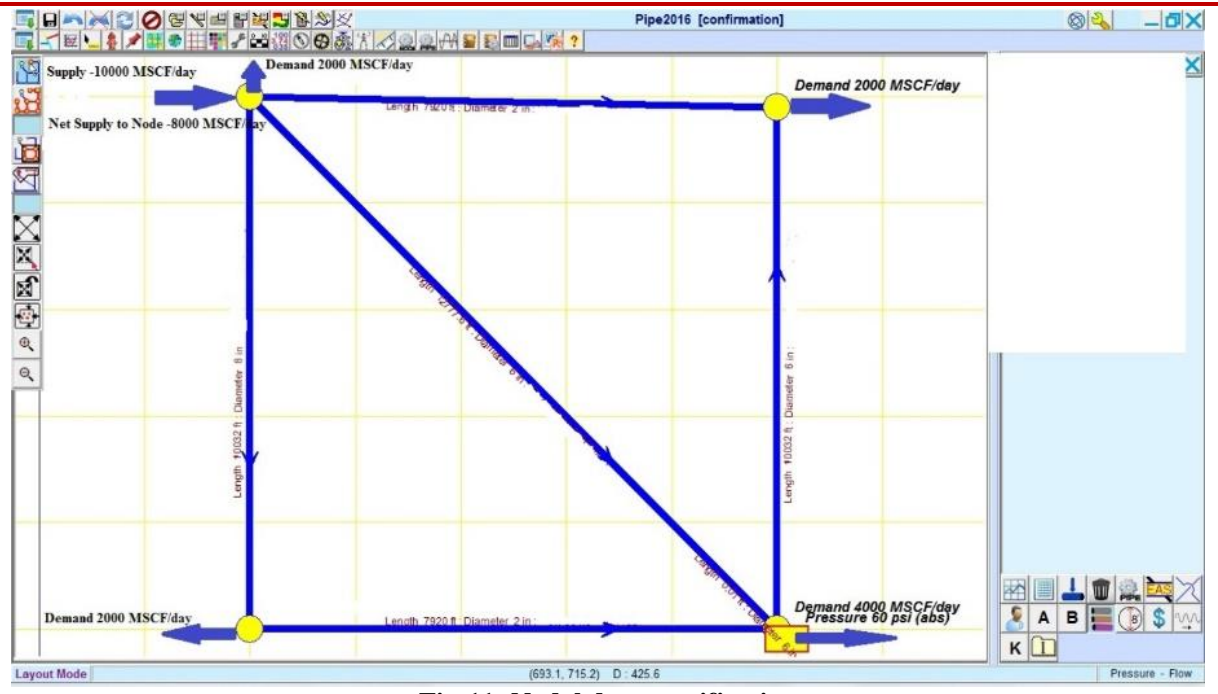

Fig-11: Nodal data specification

\section{Step 3: Analyze System and Review Results}

This was used to analyse the system for error check, unspecified paramaters and complete flow analysis of the network.
Data Check and Run Analysis: Error Check was selected under the system analysis option to check for any error in network. If errors are flagged, necessary corrections should be made so that network can be analysed. If its message "No Errors", analysis can be completed.

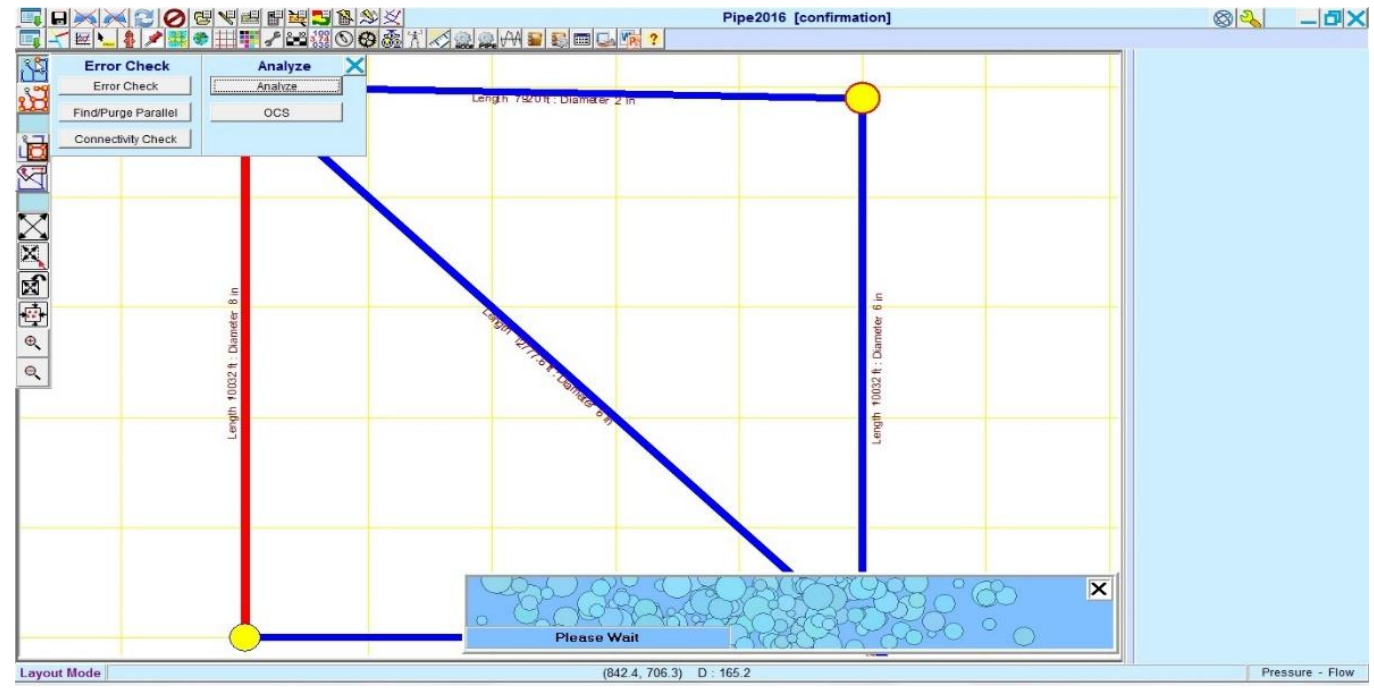

Fig-12 :Error check and analysis

\section{Result Presentation: Results Obtained are presented in subsequent section}

One-way analysis of variance (anova) test and t-test

A one-way analysis of variance test is a decision making tool used to determine the presence of statistically significant differences between the means of independent data set. It tests to validate the null hypothesis, $\mathrm{H}_{0}$;

$\mathrm{H}_{0}=\mu_{1}=\mu_{2}=\mu_{3}=\mu_{4} \ldots=\mu_{\mathrm{n}} \ldots$ equation 8

Where, $\mathrm{H}_{0}=$ Null Hypothesis $\quad \mu_{1}=$ Group mean $\mathrm{n}=$ No of data set
If, however, the test returns a statistically significant result, we accept the alternative hypothesis, $\mathrm{H}_{\mathrm{A}}$

$\mathrm{H}_{\mathrm{A}}=\mu$ is not equal

On the other hand, a T-test is used to validate the null hypothesis for two data sample, this may be done for data sample of equal or unequal variance.

The ANOVA and T-test were done using the data section of the Microsoft excel spreadsheet as shown below; For ANOVA Test

Step 1: Choose the required analysis type on the data analysis section 


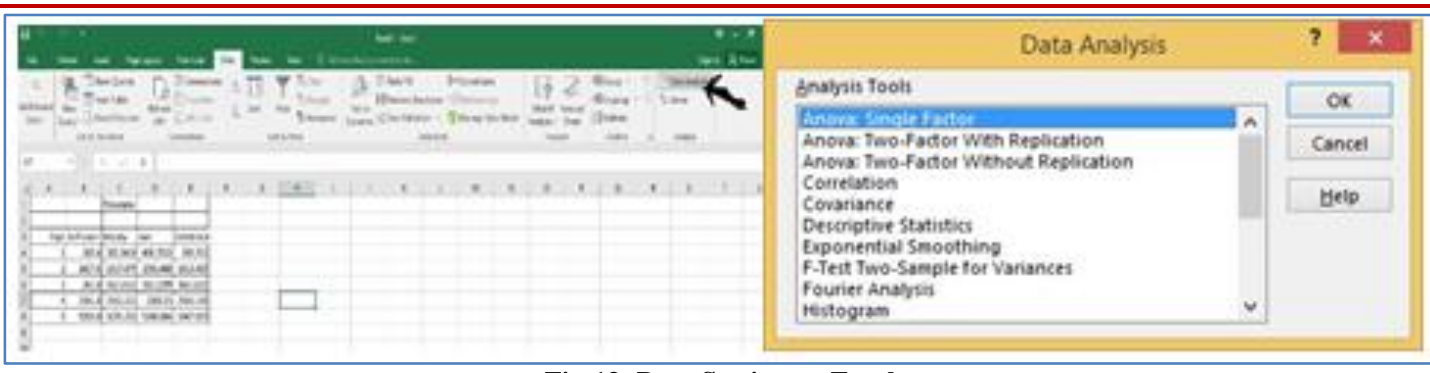

Fig-13: Data Section on Excel

Step 2: Compute the required data for analysis by selecting the column where data are assigned

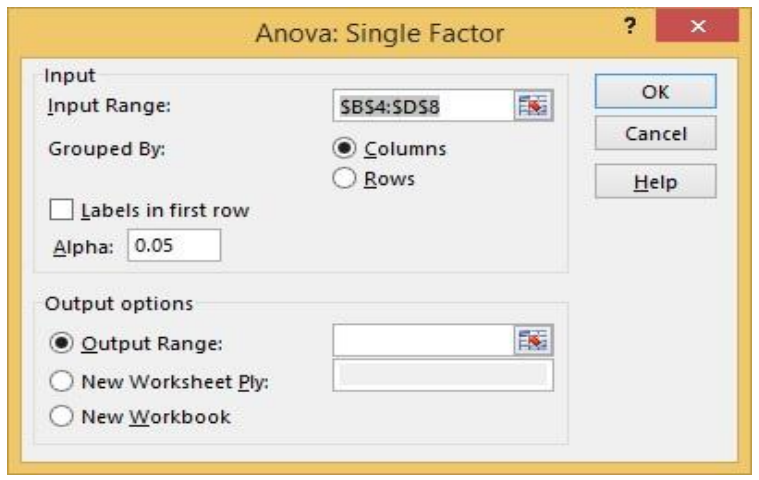

Fig-14: Computation of data

For T-Test

Step 1: F-test is first done to determine similarity of variance

Steps required are as previously itemized

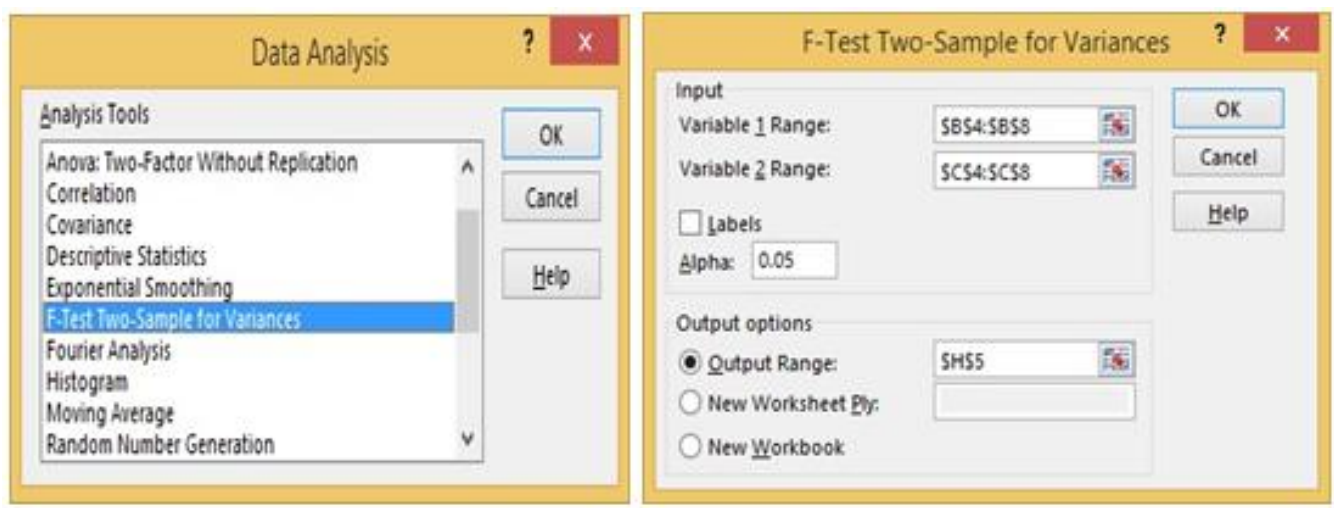

Fig-15: F-Test

Step 2: Since the variance are difference, the appropriate T-test option is selected and executed.

\begin{tabular}{|c|c|c|c|c|c|c|}
\hline \multicolumn{2}{|l|}{ Data Analysis } & ? & \multicolumn{3}{|c|}{ t-Test: Two-Sample Assuming Unequal Variances } & $x$ \\
\hline \multicolumn{2}{|l|}{ Analysis Tools } & \multirow{2}{*}{ OK } & \multirow{2}{*}{$\begin{array}{l}\text { Input } \\
\text { Variable } 1 \text { Range: } \\
\text { Variable } 2 \text { Range: }\end{array}$} & \multirow{2}{*}{$\frac{\text { SBSA:SBSS }}{\text { SCSA:SCSB }}$} & \multirow{2}{*}{$\frac{185}{186}$} & \multirow{2}{*}{$\frac{\mathrm{OK}}{\text { Cancel }}$} \\
\hline Histogran & $\wedge$ & & & & & \\
\hline Moving Averagt & & Concel & Hypothssized Mean Ditf & & & Help \\
\hline $\begin{array}{l}\text { Random Number Generation } \\
\text { Rank and Percentil. }\end{array}$ & & & $\square$ labels & & & \\
\hline Regression & & Help & Alpha: 0.05 & & & \\
\hline Sampling & & & Output options & & & \\
\hline t.Test Paired Two Sample for Means & & & - Qutput Range & soss & Tis. & \\
\hline 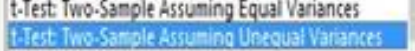 & & & New Worksheet Py: & & & \\
\hline 2-Test: Two Sample for Means & $\checkmark$ & & New Workbook & & & \\
\hline
\end{tabular}

Fig-16: T-Test 


\section{RESULTS AND DISCUSSION}

The result obtained from the various calculations are presented below

\section{Flowrate Analysis}

The value of the flowrate $(\mathrm{mscfd})$ is presented in the table below

Table-3: Calculated Flowrate (mscfd)

\begin{tabular}{|r|r|r|l|l|}
\hline Pipe & \multicolumn{1}{|c|}{ Software } & \multicolumn{1}{l|}{ Moody } & Jain & Colebrook \\
\hline 1 & 382.4 & 382.5416423 & 408.352265 & 386.5509541 \\
\hline 2 & 1617.6 & 1617.478658 & 1591.66803 & 1613.469346 \\
\hline 3 & 361.8 & 362.532074 & 383.129889 & 366.1625472 \\
\hline 4 & 2361.8 & 2362.552374 & 2383.15019 & 2366.182847 \\
\hline 5 & 5255.8 & 5255.292484 & 5208.88405 & 5247.652699 \\
\hline
\end{tabular}

Table 3 shows that all the flowrates obtained from the various friction factors compared reasonably with the software although values obtained from
Moody's Chart and Colebrook compared more accurately with the software.

\section{ANOVA Test}

Anova: Single Factor

Table-4: ANOVA Result

\begin{tabular}{|l|l|l|l|l|l|l|}
\hline SUMMARY & & & & & & \\
\hline Groups & Count & Sum & Average & Variance & & \\
\hline Software & 5 & 9979.4 & 1995.88 & 4044401.692 & & \\
\hline Moody & 5 & 9980.39723 & 1996.079446 & 4043022.963 & & \\
\hline Jain & 5 & 9975.18442 & 1995.036885 & 3939491.047 & & \\
\hline Colebrook & 5 & 9980.01839 & 1996.003679 & 4025826.667 & & \\
\hline & & & & & & \\
\hline & & & & & & \\
\hline ANOVA & & & & & & \\
\hline Source of Variation & SS & $d f$ & MS & F & P-value & F crit \\
\hline Between Groups & 3.491605528 & 3 & 1.163868509 & $2.90011 \mathrm{E}-07$ & 1 & 3.238872 \\
\hline Within Groups & 64210969.48 & 16 & 4013185.592 & & & \\
\hline & & & & & & \\
\hline Total & 64210972.97 & 19 & & & & \\
\hline
\end{tabular}

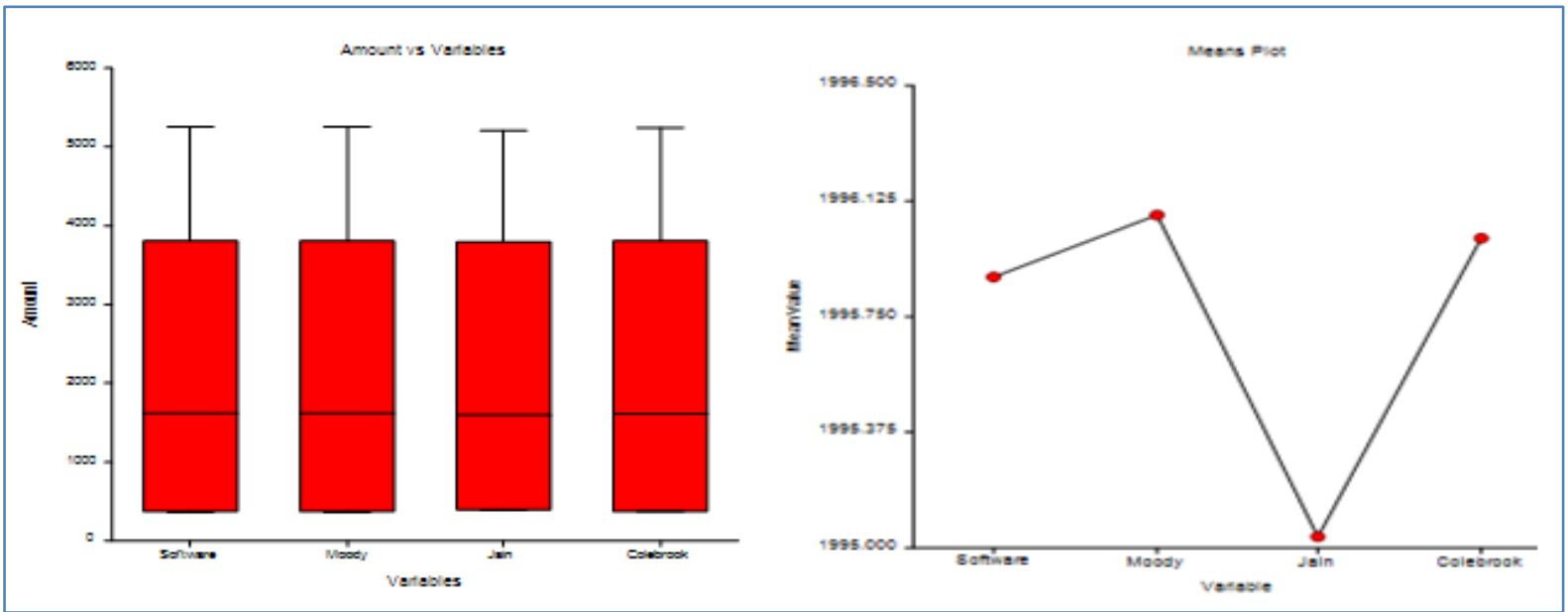

Fig-17: Box plot and mean plot from ANOVA

From Table 4; since $\mathrm{F}<$ Fcrit in the test, we accept the null hypothesis as defined in equation (8), that coupled with the box plot distribution shows that there are no statistically significant differences between the four result. The mean plot however shows that values obtained from Moody's chart and Colebrook equation are closer to the Software's result thus establishing the observation from table 3. 
OMOBOLANLE Oluwasegun Cornelious., Saudi J Eng Technol, Feb. 2020; 5(2): 49-62

T-Test

The T-Test is used to confirm the result obtained from the ANOVA test, since T-test can only be carried out on two data set, each of the friction factor outputs is compared to the software individually. Since table 4 already shows the variance is different, the result of the F-test is not computed.

Software and Moody

T-Test: Two-Sample Assuming Unequal Variances

Table-5: Software and Moody's T-test

\begin{tabular}{|c|c|c|}
\hline & Software & Moody \\
\hline Mean & 1995.88 & 1996.079446 \\
\hline Variance & 4044401.692 & 4043022.963 \\
\hline Observations & 5 & 5 \\
\hline $\begin{array}{c}\text { Hypothesized Mean } \\
\text { Difference }\end{array}$ & 0 & \\
\hline df & 8 & \\
\hline t Stat & -0.000156822 & \\
\hline $\mathrm{P}(\mathrm{T}<=\mathrm{t})$ one-tail & 0.499939357 & \\
\hline $\mathrm{t}$ Critical one-tail & 1.859548038 & \\
\hline $\mathrm{P}(\mathrm{T}<=\mathrm{t})$ two-tail & 0.999878714 & \\
\hline $\mathrm{t}$ Critical two-tail & 2.306004135 & \\
\hline
\end{tabular}

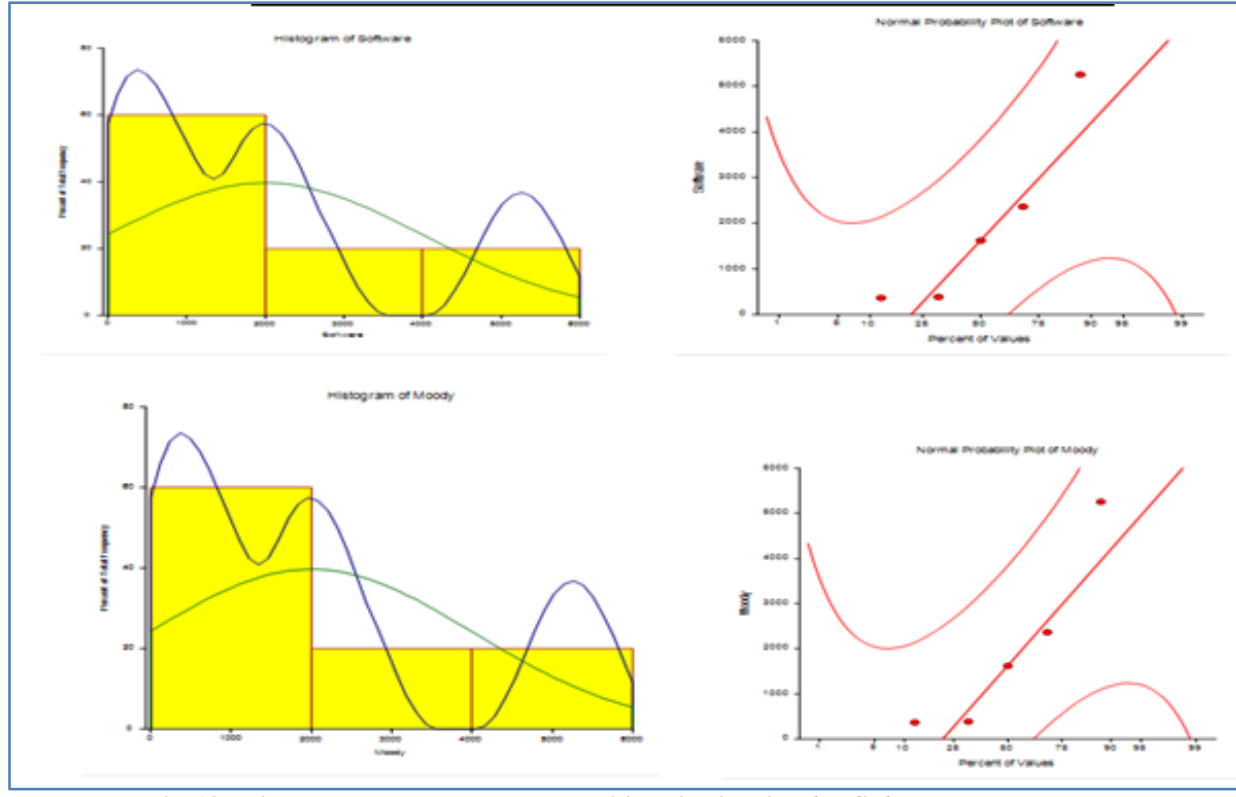

Fig-18: Histogram and Normal Probability distribution for Software and Moody

Since $t$ Stat is less than t Critical on table 5, we accept the null hypothesis, also comparisons of the superimposed density and normal density curve on the histogram shows that the results are similar.

\section{Software and Colebrook}

Variances

Table-6: Software and Colebrook's T-test

\begin{tabular}{|c|c|c|}
\hline & Software & Colebrook \\
\hline Mean & 1995.88 & 1996.003679 \\
\hline Variance & 4044401.692 & 4025826.667 \\
\hline Observations & 5 & 5 \\
\hline Hypothesized Mean Difference & 0 & \\
\hline df & 8 & \\
\hline t Stat & $-9.73502 \mathrm{E}-05$ & \\
\hline $\mathrm{P}(\mathrm{T}<=\mathrm{t})$ one-tail & 0.499962355 & \\
\hline $\mathrm{t}$ Critical one-tail & 1.859548038 & \\
\hline $\mathrm{P}(\mathrm{T}<=\mathrm{t})$ two-tail & 0.99992471 & \\
\hline $\mathrm{t}$ Critical two-tail & 2.306004135 & \\
\hline
\end{tabular}




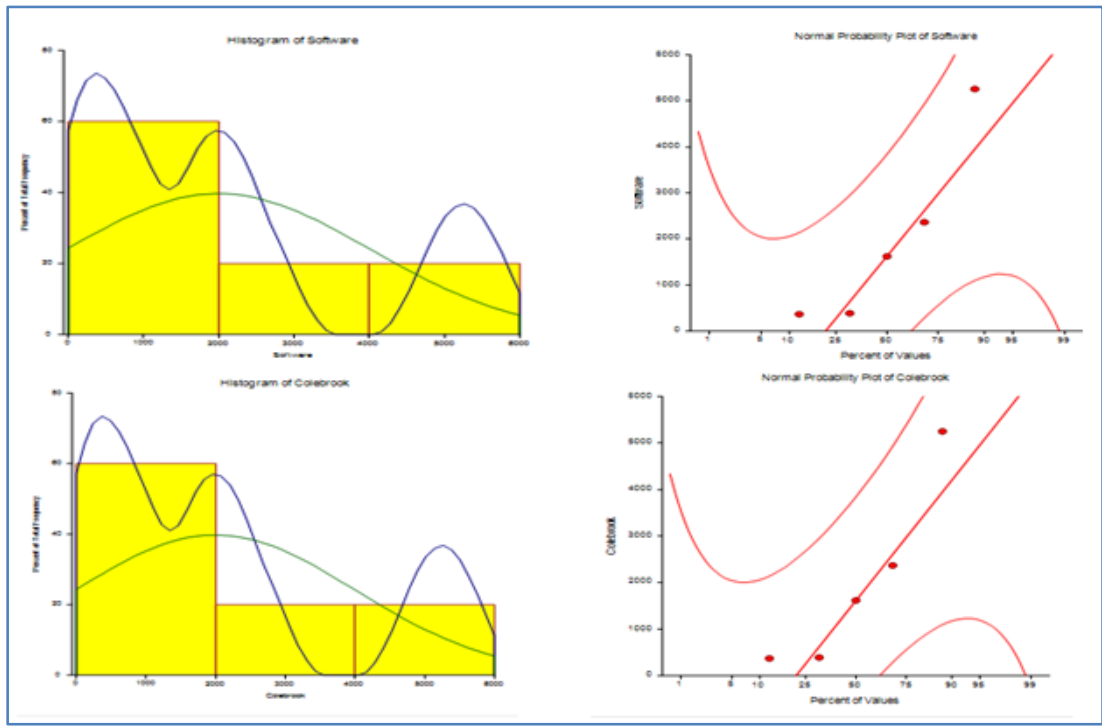

Fig-19: Histogram and Normal Probability distribution for Software and Colebrook

Data also establish the acceptance of the null hypothesis

\section{Software and Jain}

T-Test: Two-Sample Assuming Unequal Variances

Table-6: Software and Jain's T-test

\begin{tabular}{|c|c|c|}
\hline & Software & Jain \\
\hline Mean & 1995.88 & 1995.036885 \\
\hline Variance & 4044401.692 & 3939491.047 \\
\hline Observations & 5 & 5 \\
\hline Hypothesized Mean Difference & 0 & \\
\hline df & 8 & \\
\hline t Stat & 0.000667213 & \\
\hline $\mathrm{P}(\mathrm{T}<=\mathrm{t})$ one-tail & 0.499741989 & \\
\hline t Critical one-tail & 1.859548038 & \\
\hline $\mathrm{P}(\mathrm{T}<\mathrm{t})$ two-tail & 0.999483979 & \\
\hline t Critical two-tail & 2.306004135 & \\
\hline
\end{tabular}
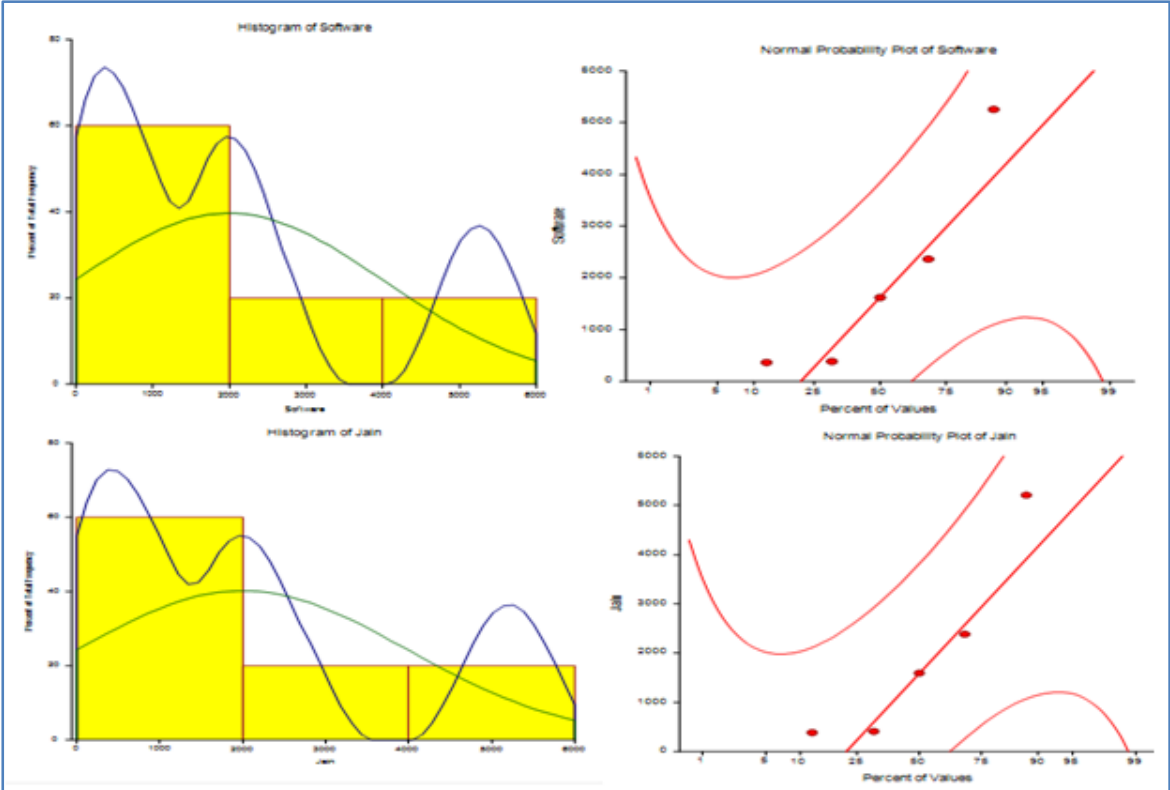

Fig-20: Histogram and Normal Probability distribution for Software and Jain 
The box plot, superimposed density and normal density plot all show that there is no problem with the normality. Also the P-value from table 4 shows that the null hypothesis cannot be rejected. In essence there is no statistically significant difference between the four results. However, the mean plot shows that the values obtained from using the Moody's Chart and Colebrook equations are closer to the software's results.

\section{CONCLUSION}

The Hardy Cross method is a powerful manual flow analysis method that is capable of giving precise and accurate result comparable to sophisticated software irrespective of the complexity or simplicity of the network as shown in this research. Nevertheless, this research has also shown that it's usage is sensitive to the choice of friction factor although the difference might not be statistically significant as shown by the ANOVA and T-test.

\section{ACKNOWLEDGEMENT}

I want to use this medium to specially appreciate Dr. Princess Nwakwo for carrying me under her wings. Also, I will like to acknowledge the love and support of my mother (Mrs F.B. Fadairo), my siblings (Mojisola and Oluwatimileyin) and Engr. Osundina for giving me a shoulder to stand on. Lastly, to great friends (Temi, Ife, Oluwadamilola and Tolu to mention a few) that have always believed in me. I say thank you.

\section{REFERENCE}

1. Chi, U. Ikoku. (1992). Natural Gas Production Engineering. Florida, USA. Krieger Publishing Company, Malabar. Originally published: New York, Wiley, (C1984, 248-290

2. Megan, E.H., \& Ethan Dursteler. (2015). Economic, Environmental and Safety Impacts of Transporting Oil and Gas in the U.S. https://www.strata.org/pdf/2017/pipelines.pdf. STRATA Publication.

3. Lopes, A.M.G. (2003). Implementation of The Hardy Cross Method for The Solution of Piping Networks. Wiley Periodicals, Inc. Comput Appl Eng Educ, 12: 117-125

4. Dejan, B. (2018). Two Efficient Methods for Gas Distributive Network Calculation; Ministry of Science and Technological Development, Beograd, Serbia.

5. Dejan, B. (2012). Gas Distribution Network Topology Problem; Mathematica Balkanica, New Series, 26, 3-4.

6. Don Wood. (2010). KY Pipe Reference Manual. https://www.kypipe.com/download

7. Don, W., Srinivasa, L., Jana, F., \& Doug, W. (2015). KYPIPE Example Manual. KYPipe, LLC; www.kypipe.com.

8. Don, W. (2010). KYPipe (Pipe 2016) software. https://www.kypipe.com/download

9. Unknown Author. (2019). FORTRAN 95 Compiler. https://www.silverfrost.com/p1001/shop/silverfrost ftn95.aspx

10. Nwajuaku, I.I., Wakawa, Y.M., Adibeli, O.J. (2017). Analysis of Head-loss Equations under EPANET and Hardy Cross Method; Saudi Journal of Engineering and Technology, scholars Middle East Publishers.

11. Adeleke, A. E., \& Olawale, S. O. A. (2013). Computer Analysis of Flow in the Pipe Network. Transnational Journal of Science and Technology, 3(2).

\section{APPENDIX}

Program used for Colebrook

Program Colebrook

Implicit none

real::f, e, d, de, Re, ee, dm, G, q, N, B !N in cp, v in $\mathrm{ft} / \mathrm{sec}, \mathrm{d}$ in $\mathrm{ft}$, de is density

! $\mathrm{G}$ is gas gravity, $\mathrm{F}$ is the initial fiction facor, $\mathrm{Y}$ is the answer from iteration

!B is colebrook friction factor, $\mathrm{Re}$ is the reynolds number

Integer:: Iteration

logical:: $Y$

$\mathrm{Y}=$.True.

print*, 'Welcome to Colebrook Friction Factor Application'

Print*, "

print*, 'enter q in mcfd, q'

Print*,"

read*, q $^{*}$

print*, 'enter the diameter in inche, $\mathrm{d}^{\prime}$

Print*,"

read*, $^{*} \mathrm{~d}$

print*, 'enter the value of the viscosity in centipose, $\mathrm{N}^{\prime}$

Print*,"

read $^{*}, \mathrm{~N}$

print*, 'enter the value of the specific gravity, G'

Print*,"

$\operatorname{read}^{*}, \mathrm{G}$

$\mathrm{de}=\mathrm{G}^{*} 0.07637$

print*, 'The density of the gas is equal to', de

Print*,"

$\operatorname{Re}=(20 * \mathrm{q} * \mathrm{G}) /(\mathrm{N} * \mathrm{~d})$

print*, 'Reynolds number is equal to', $\mathrm{Re}$

Print*,"

$\mathrm{dm}=\mathrm{d}^{*} 0.0254$

print*, 'enter corresponding roughness for pipe material, $\mathrm{e}^{\prime}$

Print*,"

read $^{*}, \mathrm{e}$

$\mathrm{ee}=\mathrm{e}^{*} 0.305$

Iteration $=0$

$\mathrm{F}=0.0056+0.5 * \operatorname{Re}^{* *}(-0.32)$

print*, 'Value of $\mathrm{f}$ is', $\mathrm{f}$

Print*,"

do while(Y)

$\mathrm{B}=(1 /(1.74$ -

$2 * \operatorname{LOG} 10((2 *(\mathrm{ee} / \mathrm{dm}))+(2.15 /(\operatorname{Re} * \operatorname{SQRT}(\mathrm{f})))))) * * 2$

Print*,'Friction factor is equal to', B 


\begin{tabular}{|c|c|}
\hline Print*," & $\operatorname{read}^{*}, \mathrm{q}$ \\
\hline $\begin{array}{l}\text { Print*, 'The result generated will be used for the next } \\
\text { iteration' }\end{array}$ & $\begin{array}{l}\text { print*, 'enter the diameter in inche, d' } \\
\text { print*, " }\end{array}$ \\
\hline Print*," & $\operatorname{read}^{*}, \mathrm{~d}$ \\
\hline if $(\mathrm{F}==\mathrm{B})$ then & print ${ }^{*}$, 'enter the value of the viscosity, $\mathrm{N}^{\prime}$ \\
\hline$Y=$ false & print*, " \\
\hline else & $\operatorname{read}^{*}, \mathrm{~N}$ \\
\hline $\mathrm{F}=\mathrm{B}$ & print*, 'enter the value of the specific gravity, G' \\
\hline Iteration=Iteration +1 & print*, " \\
\hline Print*, 'Iteration', Iteration & $\operatorname{read}^{*}, \mathrm{G}$ \\
\hline$Y=$. True. & print*," \\
\hline end if & $\mathrm{Re}=(20 * \mathrm{q} * \mathrm{G}) /(\mathrm{N} * \mathrm{~d})$ \\
\hline end do & print*, 'Reynolds number is equal to', Re \\
\hline print*, 'The friction factor using Colebrook is given as', & print*, " \\
\hline $\mathrm{F}$ & $\mathrm{dm}=\mathrm{d} * 0.0254$ \\
\hline $\begin{array}{l}\text { print*, 'Thank you' } \\
\text { end program Colebrook }\end{array}$ & $\begin{array}{l}\text { print*, 'enter corresponding roughness for pipe material, } \\
\mathrm{e}^{\prime}\end{array}$ \\
\hline & print*, " \\
\hline Program used for JAIN & $\operatorname{read}^{*}, \mathrm{e}$ \\
\hline program Jain & $\mathrm{ee}=\mathrm{e}^{*} 0.305$ \\
\hline implicit none & $\mathrm{F}=\left(1 /\left(1.14-\left(2 * \mathrm{LOG} 10\left((\mathrm{ee} / \mathrm{dm})+\left(21.25 / \mathrm{Re}^{* *} 0.9\right)\right)\right)\right)\right) * * 2$ \\
\hline real::f, e, d, Re, G, q, N, dm, ee ! $\mathrm{N}$ in $\mathrm{cp}, \mathrm{v}$ in $\mathrm{ft} / \mathrm{sec}, \mathrm{d}$ in & print*, 'Value of $\mathrm{f}$ is', $\mathrm{f}$ \\
\hline $\mathrm{ft}, \mathrm{dm}$ is diameter in meter, ee is the roughness in meter, & print*, " \\
\hline $\mathrm{G}$ is gas gravity & print*, 'The friction factor using Jain is given as', $\mathrm{f}$ \\
\hline $\begin{array}{l}\text { print*, 'Welcome to Jain Friction Factor Application' } \\
\text { print*," }\end{array}$ & $\begin{array}{l}\text { print*, " } \\
\text { print*, 'Thank you' }\end{array}$ \\
\hline print*, 'enter q in mcfd, q' & END PROGRAM JAIN \\
\hline
\end{tabular}

